\title{
COLD FLOW NUMERICAL ANALYSIS OF GAS MICROTURBINE COMBUSTION CHAMBER THROUGH CFD TOOL
}

\author{
G. K. Caetano ${ }^{\mathrm{a}}$, \\ J. F. T. de Carvalho ${ }^{b}$, \\ and J. S. Rosa ${ }^{a}$ \\ ABSTRACT \\ Gas turbines are equipment used mainly in the generation of electric energy. \\ They have as one of their main components the combustion chamber. \\ Therefore, it is relevant to study the characteristics of this component, in \\ order to reach a satisfactory operation. In this context, this paper presents an \\ analysis of a combustion chamber applied to a gas turbine with a cold flow \\ approach using the numerical theoretical method, through the computational \\ fluid dynamics technique. In this experiment, the software Abaqus CFD \\ (computational fluid dynamics) - present in the 3DExperience platform - \\ and the finite volume method are used. The objective was to evaluate the \\ flow, pressure and velocity profiles during the single-phase flow. The gas \\ turbine prototype is configured using a combustion chamber of reverse flow \\ type in order to decrease flow velocity and increase the combustion \\ efficiency. Based on input data obtained from practical experiments, the \\ calculation of the number and Reynolds confirmed - according to the \\ literature of fluid mechanics - the occurrence of a flow classified as \\ turbulent, with chaotic and random motion, what allows defining the ideal \\ point of injection from analysis of velocity plots with stream lines. In \\ addition, a Mach number smaller than 0.3 confirms the theory of having an \\ incompressible flow, in which compressibility effects can be disregarded. \\ The analysis of mass flow rates of the combustion zones made it possible to \\ evaluate maximum differences of $3 \%$ between the design data and the one \\ found in the study. To determine the inherent error of the mesh in the CFD \\ study was calculated through the grid conference method, the value found \\ was around $2.68 \%$. \\ Received: February 28, 2019 \\ Revised: March 20, 2019 \\ Keywords: CFD; gas turbine; combustion chamber; numeric simulation \\ Accepted: April 11, 2019
}

\author{
Subscripts \\ CR combustion region \\ max maximum \\ med medium
}

\section{INTRODUCTION}

Gas microturbines (GMT) have been of interest to many researchers in recent times, since they are a form of energy generation that can use renewable fuels. Moreover, it provides benefits such as low emissions, compact size, easy installation and minimized operation, noise and vibrations, as well as high density power and reduced operating and maintenance costs (Zainal, 2017).

The combustion chamber of a gas microturbine is one of the main components to evaluate its performance, as evidenced by Chmielewski and Gieras (2017). Experimentally, the study of the geometry of the combustion chamber can provide important benefits to the system, such as reduction of $\mathrm{NO}_{\mathrm{X}}$ and $\mathrm{CO}$ emissions and performance enhancements by controlling temperatures and pressures. Kruse (2015) - aspiring to measure of $\mathrm{NO}_{\mathrm{X}}$ and $\mathrm{CO}$ emissions in combustion chambers - 
proposed a evaluation of the influence of pressures on combustion processes. The results pointed to improvements in gas recirculation and a more efficient burning of the air-fuel mixture.

In addition to the experimental study, the use of computational fluid dynamics (CFD) tools allows the analysis of different types and engineering situations, in which, otherwise, the experiments costs would be too high. Moreover, even characterize and obtain results would be too difficult. Numerical analysis performed by Kjaer et al. (2018) showed that - by using CFD - it was possible to evaluate flow profiles and, mainly, to analyze geometric variations in order to control the desired temperature, besides reducing losses in a chamber design of a grain dryer in a compressible and turbulent flow. Zainal (2017) used CFD tools to assess the performances of different geometries of combustion chambers, aiming to find an ideal design that meets $\mathrm{CO}$ emissions and turbine inlet temperatures, specified through the evaluation of the flow, as well as properties such as temperature, pressure, output and speed in the combustion chamber zones.

Given the need to seek alternatives for the electric power generation and the crescent scientific relevance been given for the study of GMT in this context, it is also necessary to study and evaluate the project of each component of a GMT. In this sense, this work aims to evaluate - through the numerical CFD method of a prototype gas microturbine combustion chamber built to verify flow profiles in combustion zones - the velocity and pressure of a cold flow in order to confirm the theory about the model studied.

The combustion chambers of gas turbines are components that must be evaluated in detail, given their specific function of receiving the air coming from the compressor, mixing it with the fuel in a homogeneous way and, finally, combusting this mixture. Consequently, it produces gases with high temperature towards the turbine, which performs the work per se. This type of equipment operates with a high excess of air, which can be an obstacle to the combustion. For combustion to occur satisfactorily, based on a homogeneous air / fuel mixture, the chamber needs to receive the air with an increased level of turbulence - along with a reduced speed - so that it provides a complete and continuous burning of the mixture. To do so, the design of a combustion chamber is carried out by dividing it into different zones: primary, secondary and tertiary (Silva, 2013).

According to Lefebvre and Ballal (2010), the zones can also be denominated as primary, intermediate and dilution zone, as exemplified in Fig. 1. In the primary zone, there ought to be a recirculating flow with a low speed, because it is necessary to sustain the flame on different ranges of engine operation. The intermediate zone provides a more gradual reduction of temperature, since a more abrupt form can generate $\mathrm{CO}_{2}$, which decreases the machine efficiency. Usually, the intermediate zone is applied in combustion chambers that work with a temperature above $1727^{\circ} \mathrm{C}$ in the primary zone. The dilution zone is a stage where another percentage of air is admitted to the combustion gases so that the temperature is partially reduced, putting the flow under acceptable conditions to pass through the turbine.

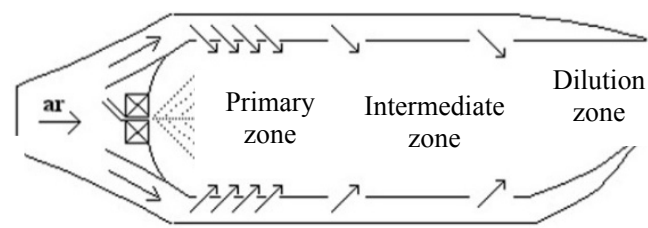

Figure 1. Details of a gas microturbine combustion chamber.

According to Çengel and Boles (2013), the fluid inlet temperature in the turbine is an important factor for performance evaluation. There are limitations to the temperature rising in a disorderly way, since the components of the turbine need to be resistant to these temperatures. Therefore, evaluations of how a flow develops, its operation speed and temperatures during the cycle are extremely relevant.

The combustion chamber evaluated in this work, called Dump, consists of the annular type of reverse flow, normally used in engines with low mass flow of incoming air. In this specific case, the air intake occurs in a 90 degree rotation, flowing outward of the combustion chamber. This movement characterizes it as reverse flow and happens, precisely, so that a decrease in the flow velocity occurs to cause turbulence.

In its original design, the chamber contains three stages of air intake in the combustion region. The flows, proportionally, must be: $30 \%$ in the primary entrance, $20 \%$ in the intermediate zone and $50 \%$ in dilution zone.

\section{EXPERIMENTS}

The studied model was built in CAD 3D software, what can be observed in Fig. 2 with an isometric and exploded view for understanding the parts of the assembly.

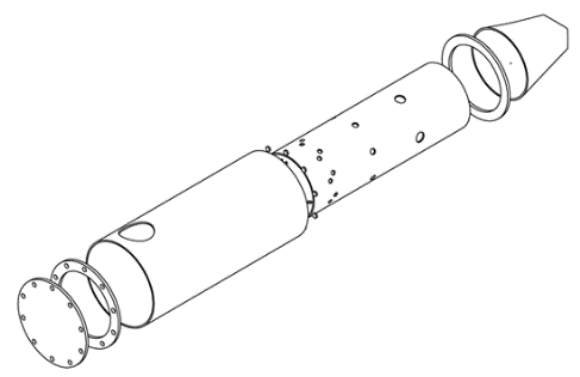

Figure 2. Isometric (a) and exploded (b) view of the combustion chamber. 
In Fig. 3 the fluid inlet, outlet and the combustion regions are indicated.

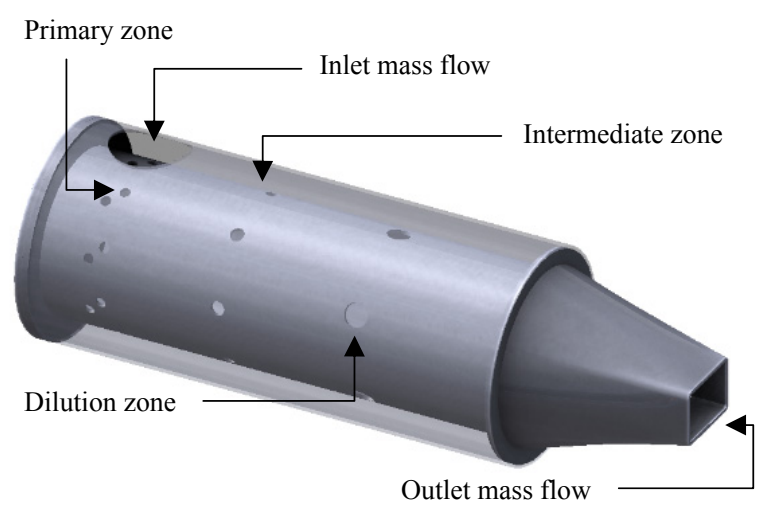

Figure 3. Isometric view showing the regions of the study.

Figure 4 corresponds to a specific view of the flame tube, the main component of this study. By analyzing the inflow and outflow indications, it is possible to verify that this component is responsible for the air intake, and it is also the place where the injection of fuel for combustion occurs. The gases, after combustion, are directed to the nozzle, which, in a complete GMT assembly, is coupled to the turbine itself, responsible for the work.

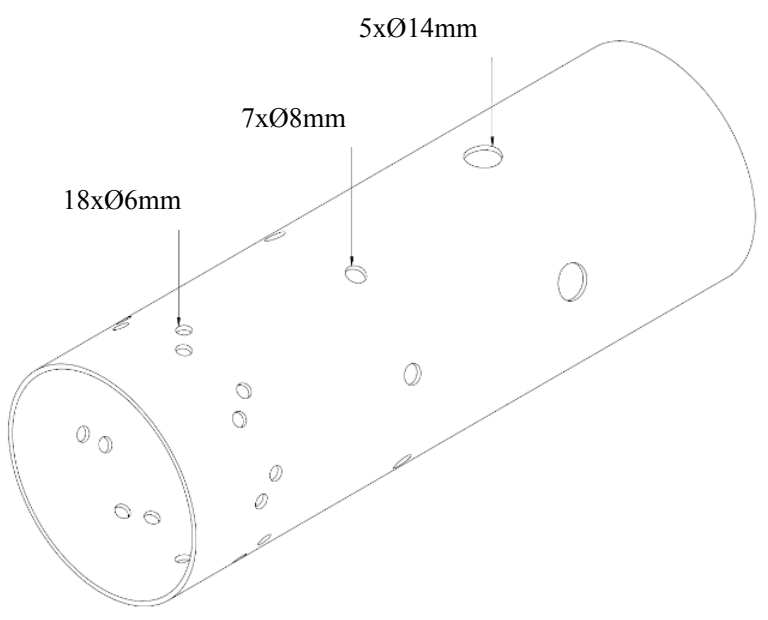

Figure 4. Isometric view of the flame tube.

As noted, there are three known zones in the combustion chamber. Therefore, the chamber ends up with three air inlet stages in the combustion region due to boreholes. Table 1 highlights the drillings, measurements and quantities in the studied model.

Table1. Size and quantity of combustion chamber holes.

\begin{tabular}{|c|c|c|}
\hline Holes & Size $(\varnothing)$ & Quantity \\
\hline Hole 1 (Primary) & $6 \mathrm{~mm}$ & 18 \\
\hline Hole 2 (Intermediate) & $8 \mathrm{~mm}$ & 7 \\
\hline Hole 3 (Dilution) & $14 \mathrm{~mm}$ & 5 \\
\hline
\end{tabular}

For the study of the flow, the fluid was modeled as air and its properties in the input are presented in Tab. 2. The parameters of the input boundary of the control volume are also shown in this table.

Table 2. Air properties and parameters at the input boundary of the control volume.

\begin{tabular}{|c|c|c|c|}
\hline Properties & Input & Output & \\
\hline Pressure & 202.6 & 101.3 & $\mathrm{kPa}$ \\
\hline Temperature & 25 & 25 & ${ }^{\circ} \mathrm{C}$ \\
\hline $\begin{array}{c}\text { Especific mass } \\
\text { (air) }\end{array}$ & 1.205 & 1.205 & $\mathrm{~kg} / \mathrm{m}^{3}$ \\
\hline Velocity & 30 & - & $\mathrm{m} / \mathrm{s}$ \\
\hline Área (section) & 1689.90 & 1284.62 & $\mathrm{~mm}^{2}$ \\
\hline
\end{tabular}

With standard air modeling, the effects of combustion were neglected. The fluid flow was modeled in a monophasic, incompressible and turbulent way, for the permanent operating regime. To meet these conditions in numerical form, it is necessary to meet the resolution of a set of equations of mass, energy and momentum conservation, as well as the Reynolds Number and Mach Number.

The equation of energy, from the first law of thermodynamics, is given by equation:

$$
\int_{S} \rho C_{p} \theta v \cdot n d S=\int_{V} r d V-\int_{S} q \cdot n d S
$$

where $C p$ is the specific heat, $\theta$ is the temperature, $q$ is the heat flow due to conduction defined by the Fourier law and $r$, the heat supplied externally to the body per unit volume.

The integral form of the movement conservation equation can be verified in the the following equation:

$$
\int_{S} \rho v \otimes v . n d S=\int_{V} \nabla \rho d V+\int_{S} \tau \cdot n d S \int_{V} f d S
$$

where $V$ is arbitrary control volume with surface area $S, \rho$ is the specific mass of the fluid, $P$ is pressure, $v$ is velocity in vector, $v_{m}$ is the velocity of the moving mesh, $f$ is the force of the body and $\tau$ is the viscous shear stress.

For characterization of the flow regime as laminar, transitory and turbulent, the Reynolds number is used, as seen in equation:

$$
\mathrm{Re}=\frac{\rho V L}{\mu}
$$

where $V$ is the flow velocity, $L$ is the characteristic length scale of the problem and $\mu$, viscosity. According to Brunetti (2008), in the case of tubes, the flow classification is: when $\operatorname{Re}<2000$, there is a laminar flow; when $2000<\operatorname{Re}<2400$, the flow is transient and $\operatorname{Re}>2400$ classifies a flow as turbulent. 
The Mach number is a dimensionless measure that represents a relation between flow and sound velocities, as equation:

$$
M_{a}=\frac{V}{C}
$$

The Mach number varies locally in the flow, normally due to temperature and pressure. With Mach number smaller than 0.3 , a flow is defined as incompressible.

The model was described through a mesh of predominantly hexahedral elements that have an 8node element, shown in Fig. 5.

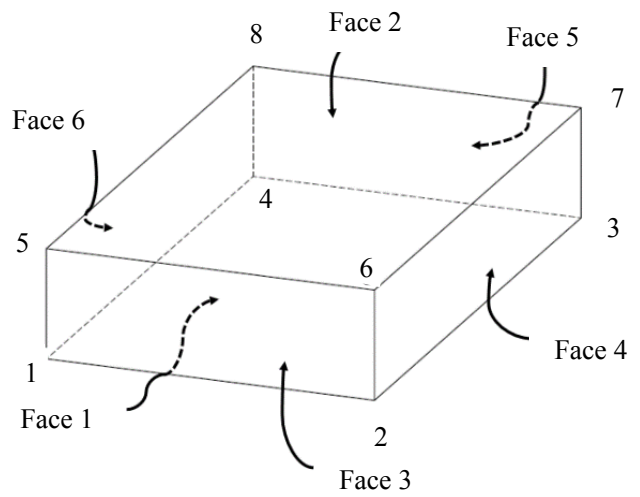

Figure 5. Hexahedral mesh element.

The mesh generated with refinements in the regions near the walls, small spacings and regions of interest as flow areas between components, as can be seen in Fig. 6.
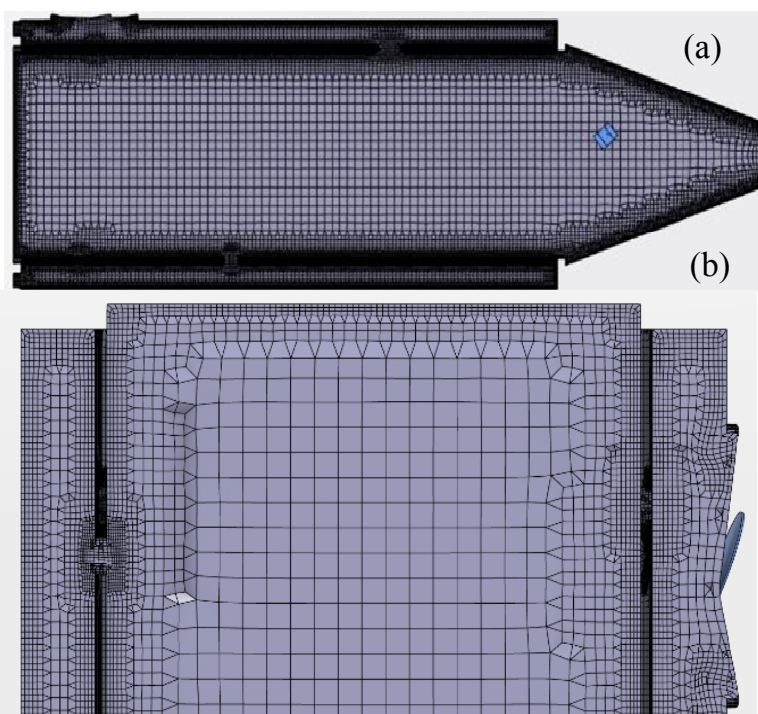

Figure 6. Section view of the mesh in (a) and detail of the primary zone of the flame tube in (b).

Table 3 lists the information on the hexahedral mesh created and used in the study. A computational time of 320 minutes was applied to run the study.
Table 3. Details of the mesh used in the CFD study.

\begin{tabular}{|c|c|c|c|}
\hline $\begin{array}{c}\text { Elements } \\
\text { number }\end{array}$ & $\begin{array}{c}\text { Nodes } \\
\text { number }\end{array}$ & $\begin{array}{c}\text { Minimum } \\
\text { element size }\end{array}$ & $\begin{array}{c}\text { Minimum } \\
\text { element size }\end{array}$ \\
\hline 3695181 & 3516301 & $1 \mathrm{~mm}$ & $5 \mathrm{~mm}$ \\
\hline
\end{tabular}

As suggested by Lefebvre and Ballal (2010), a recirculating and turbulent flow should be obtained in the combustion region of the chamber. Therefore, to describe this behavior the turbulence model k- $\omega$ SST is used.

To determine the inherent error of the mesh, a study was carried out comparing different meshes with distinct levels of refinements. In this context, the mesh data was used by Roache (2008) in an evaluation with the Grid Convergence Method (GCI).

\section{RESULTS AND DISCUSSION}

Based on an inlet pressure of 2 bar - a velocity input parameter of $30 \mathrm{~m} / \mathrm{s}$ - a maximum flow velocity of approximately $70 \mathrm{~m} / \mathrm{s}$ are obtained. Fig. 7 shows three velocity plots through a color diagram (plot with velocity between 0 and $70 \mathrm{~m} / \mathrm{s}$ ).

As expected, a decrease in velocity in the central region is observed in (a). In (b) and (c) through the vortices of the vectors and, especially, through the stream lines - it is shown that the flow has vortex and swirling regions, what configures a chaotic behavior, typical of turbulent flows.

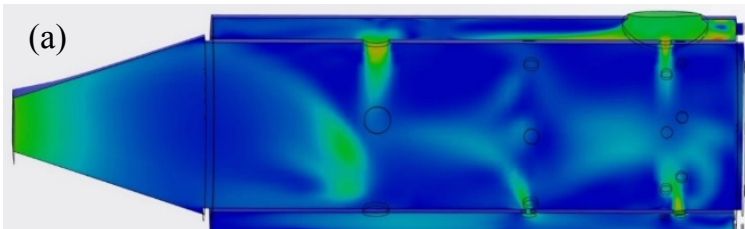

(b)
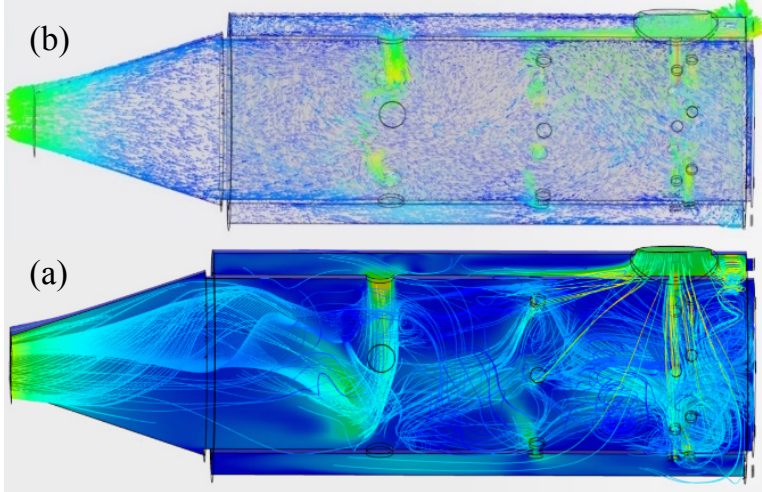

Figure 7. Velocity plots: (a) velocity color diagram, (b) flow vectors and (c) stream lines.

Considering the dynamic viscosity of the air, the outlet nozzle diameter, the specific mass of the air, the atmospheric pressure, the temperature of $20^{\circ} \mathrm{C}$ and the maximum speed, according to Tab. 4, a Reynolds number of approximately 154642 was obtained, which indicates a turbulent flow. When assuming the diameter of the combustion region (CR) highlighted in Fig. 8 (a) and the average velocity in 
the same location, according to data from Tab. 4, a Reynolds number of about 141587 is obtained.

Table 4. Parameters for Reynolds number definition.

\begin{tabular}{|c|c|c|}
\hline Property & Value & Unity \\
\hline$\mu$ & $1.2 \times 10-5$ & $\mathrm{~m} 2 . \mathrm{s}^{-1}$ \\
\hline$\varnothing_{\text {nozzle }}$ & 22 & $\mathrm{~mm}$ \\
\hline$\varnothing_{\mathrm{CR}}$ & 94 & $\mathrm{~mm}$ \\
\hline$\rho$ & 1.205 & $\mathrm{~kg} \cdot \mathrm{m}^{-3}$ \\
\hline $\mathrm{V}_{\max }$ & 70 & $\mathrm{~m} \cdot \mathrm{s}^{-1}$ \\
\hline $\mathrm{V}_{\operatorname{med}} \mathrm{CR}$ & 15 & $\mathrm{~m} \cdot \mathrm{s}^{-1}$ \\
\hline
\end{tabular}

Starting from the average velocity of the flow near the nozzle of $50 \mathrm{~m} / \mathrm{s}$ and the sound speed, a Mach number of 0.147 is found, which confirms the expectation of having an incompressible flow.

By showing the stream lines more densely, it can be more easily understood how the flow occurs over the combustion chamber. As described above, the reverse chamber type is used to create a turbulence region in the area highlighted in Fig. 8. The reason for that is to reduce the speed to obtain a smooth, gradual and continuous combustion of the air-fuel mixture, a result that is confirmed.

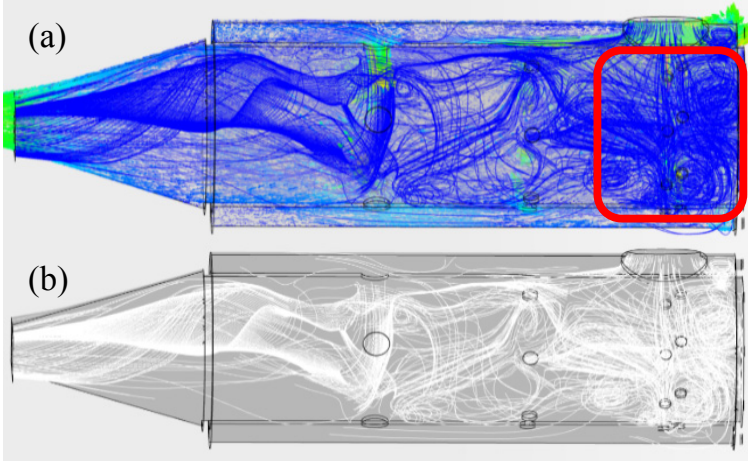

Figure 8. Details of stream lines in velocity diagram (velocity between 0 and $70 \mathrm{~m} / \mathrm{s}$ ) in (a) and detailing only stream lines in (b)

Figure 9 shows a cross-sectional view of the holes of the primary zone, which is divided into two rows. In (a) and (b), the first and second rows of holes are respectively formed. As can be seen, the holes in this zone are the ones closest to the inlet of the fluid flow in the chamber and, therefore, generate the highest velocity. Because of the holes' position, the flow is quite chaotic. On one hand, the ones located on the left side of Fig. 9, have a normal orientation to the hole, since they are located on the opposite side of the influx. On the other hand, the holes closest to the inlet generate an inclined flow because of the direction in which the fluid is injected into the chamber.

With these data, it can be inferred that the ideal fuel injection point would be the displaced location of the center, highlighted in Fig. 9, since, in this region, there is a reduction of the flow velocity. Consequently, this causes an increase of pressure that, in contact with the fuel, tends to favor combustion.
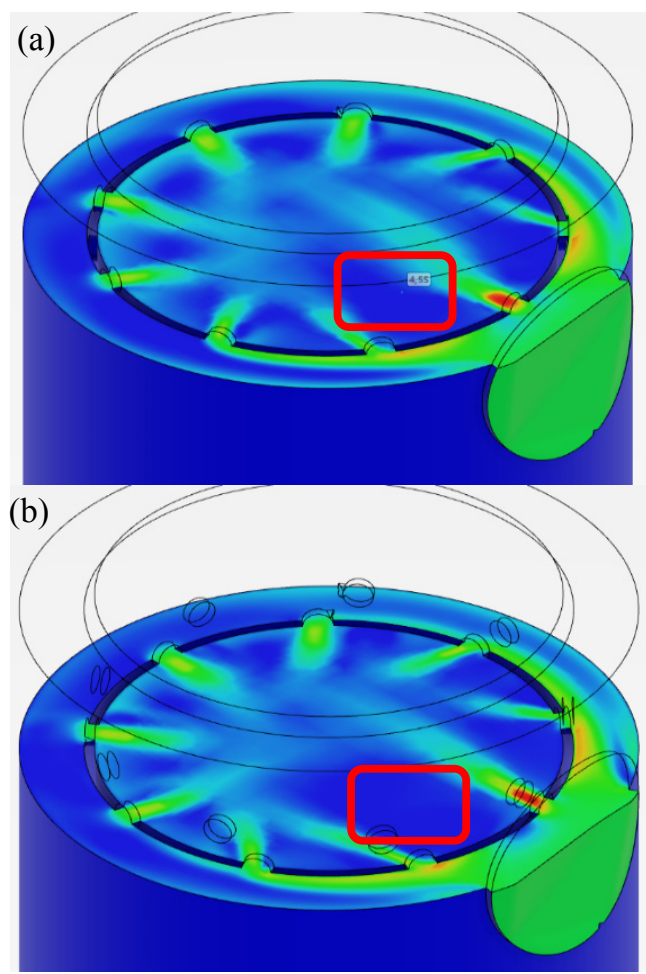

Figure 9. Cut-view of the holes in the first (a) and second (b) rows of the primary zone of the flame tube showing the plot with velocity between 0 and $70 \mathrm{~m} / \mathrm{s}$.

The pressure diagrams indicated in Fig. 10 show that the higher pressures are observed at the system inlet until the division with the combustion region itself. In the outlet nozzle containing the higher velocities shown in Figures 7 and 8, since these properties are analogous, a higher pressure develops in the regions of slower velocity, while a higher velocity generates lower pressures. The decrease of outflow generated by the nozzle is also responsible for an increase in velocity, due to it being a permanent regime.

As expected, consequently, the lowest pressures of the system are generated in the nozzle, as can be seen in Fig. 10, which shows a gauge pressure diagram with values between 0 and $4500 \mathrm{~N} / \mathrm{m}^{2}$.

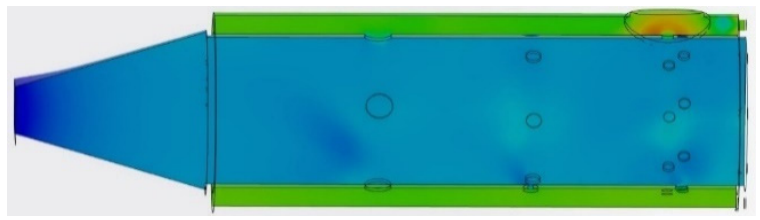

Figure 10. Color diagram indicating flow pressure distribution.

Based on the input area, the density and velocity of the fluid has a mass flow rate of $61.09 \times 10^{-3} \mathrm{~kg} / \mathrm{s}$ at the combustion chamber inlet. In order to evaluate 
the mass flow rates in each combustion zone according to the design, Tabs. 5, 6 and 7 detail the average velocities and respective mass flow rates of each hole in the combustion zones.

Table 5 describes a total mass flow rate of $19.68 \times 10^{-3} \mathrm{~kg} / \mathrm{s}$ in the primary zone, corresponding to approximately $32 \%$ of the inlet flow, close to the project value of $30 \%$.

Table 5. Velocity and corresponding mass flow in the holes of the two rows of the primary zone of the flame tube.

\begin{tabular}{|c|c|c|c|}
\hline $\begin{array}{c}\text { Velocity } \\
1^{\mathrm{a}} \text { row } \\
(\mathrm{m} / \mathrm{s})\end{array}$ & $\begin{array}{c}\text { Flow rate } \\
\left(.10^{-3} \mathrm{~kg} / \mathrm{s}\right)\end{array}$ & $\begin{array}{c}\text { Velocity } \\
2^{\mathrm{a}} \text { row } \\
(\mathrm{m} / \mathrm{s})\end{array}$ & $\begin{array}{c}\text { Flow rate } \\
\left(.10^{-3} \mathrm{~kg} / \mathrm{s}\right)\end{array}$ \\
\hline 32 & 1.09 & 32 & 1.09 \\
\hline 29 & 0.99 & 28 & 0.95 \\
\hline 33 & 1.12 & 31 & 1.06 \\
\hline 32 & 1.09 & 33 & 1.12 \\
\hline 32 & 1.09 & 31 & 1.06 \\
\hline 32 & 1.09 & 31 & 1.06 \\
\hline 34 & 1.16 & 30 & 1.02 \\
\hline 32 & 1.09 & 28 & 0.95 \\
\hline 40 & 1.36 & 38 & 1.29 \\
\hline \multicolumn{3}{|c|}{ Total mass flow } & 19.68 \\
\hline
\end{tabular}

Table 6 describes a total mass flow rate for the intermediate zone of $13.99 \times 10^{-3} \mathrm{~kg} / \mathrm{s}$, which corresponds to approximately $22 \%$ of the inlet flow, close to the project value of $20 \%$.

Table 6. Velocity and corresponding mass flow in the holes of the intermediate zone of the flame tube.

\begin{tabular}{|c|c|}
\hline Velocity $(\mathrm{m} / \mathrm{s})$ & Flow rate $\left(.10^{-3} \mathrm{~kg} / \mathrm{s}\right)$ \\
\hline 32 & 1.94 \\
\hline 33 & 2.00 \\
\hline 34 & 2.06 \\
\hline 34 & 2.06 \\
\hline 32 & 1.94 \\
\hline 34 & 2.06 \\
\hline 32 & 1.94 \\
\hline Total mass flow & 13.99 \\
\hline
\end{tabular}

Table 7 describes a total mass flow rate for the dilution zone of $30.42 \times 10^{-3} \mathrm{~kg} / \mathrm{s}$, corresponding to approximately $49 \%$ of the inlet flow rate, close to the project value of $50 \%$.

Table 7. Velocity and corresponding mass flow in the holes of the dilution zone of the flame tube.

\begin{tabular}{|c|c|}
\hline Velocity $(\mathrm{m} / \mathrm{s})$ & Flow rate $\left(.10^{-3} \mathrm{~kg} / \mathrm{s}\right)$ \\
\hline 32 & 5.94 \\
\hline 35 & 6.49 \\
\hline 34 & 6.31 \\
\hline 30 & 5.56 \\
\hline 33 & 6.12 \\
\hline Total mass flow & 30.42 \\
\hline
\end{tabular}

In terms of mesh, its quality was investigated through the determination of its inherent error. A study to each case was carried out by comparing different meshes with distinct levels of refinements. Three individual studies to each case were performed through the usage of different mesh refinements to minimum element size. Divergent numbers of elements were elaborated to evaluate the maximum velocity in the flow. Table 8 describes the data used for the chosen evaluation method, GCI where $\mathrm{N}$ is the mesh cell numbers, $\phi$ is the maximum velocity and $\mathrm{h}$ is the grid size.

Table 8. GCI Calculation data from the CFD Mesh Study.

\begin{tabular}{|c|c|c|c|c|}
\hline & Mesh & $\mathrm{N}$ & $\phi$ & $\mathrm{h}$ \\
\hline 1 & Thick & 1459750 & $65 \mathrm{~m} / \mathrm{s}$ & 0.0005104 \\
\hline 2 & Intermediate & 2319442 & $68.5 \mathrm{~m} / \mathrm{s}$ & 0.0006637 \\
\hline 3 & Slim & 3695181 & $70 \mathrm{~m} / \mathrm{s}$ & 0.0008277 \\
\hline
\end{tabular}

Three meshes with divergent numbers of elements ( $\mathrm{N}$ in Tab. 8) were elaborated to evaluate the maximum speed in the flow. The table data set a GCI around $2.68 \%$.

\section{CONCLUSIONS}

According to the bibliography analyzed, it is noticeable the presence of vortices and a chaotic behavior in the inner region of the combustion chamber - typical of a turbulent flow - since they are imperative for the gradual, uniform and continuous combustion of the air/fuel mixture. Furthermore, from the calculation of the Reynolds number, it is confirmed that the flow - in any of the moments and regions of the study - has a value greater than 2400 , which, based on literature, characterizes it as turbulent. It explains the flow profiles verified in the diagrams of stream lines, which is desired for this type of combustion chamber.

From the Mach number analysis of less than 0.3 , the theory of working with a flow in which the effects of compressibility are small and can be disregarded, treating the flow as incompressible, is confirmed.

The study also proved the existence of a link between properties such as pressure and velocity, which are analogous, as well as stream lines indicating a desired flow profile.

Since the combined areas of the holes in each combustion zone do not exactly correspond to the respective proportion of $30 \%, 20 \%$ and $50 \%$ of the primary, intermediate and dilution zones in relation to the input area, the mass flow values found demonstrate that geometric and contour conditions of the study can meet the project requirements.

\section{ACKNOWLEDGEMENTS}

We thank SKA Automação de Engenharias for 
lending Abaqus/CFD license present on the 3 Experience platform used in numerical analysis.

\section{REFERENCES}

Brunetti, F., 2008, Mecânica dos Fluidos, São Paulo, Pearson Prentice Hall. (in Portuguese)

Çengel, Y. A., and Boles, M. A., 2013, Termodinâmica, Porto Alegre, Amgh. (in Portuguese)

Chmielewski, M., and Gieras, M., 2017, Impact of Variable Geometry Combustor on Performance and Emissions from Miniature Gas Turbine Engine, Journal of the Energy Institute, Vol. 90, pp. 257-264. DOI:10.1016/j.joei.2016.01.004

Kjaer, L. S., Poulsen, M., Sorensen, K., and Condra, T., 2018, Modelling of Hot Air Chamber Designs of a Continuous Flow Grain Dryer, Engineering Science and Technology. DOI:10.1016/j.jestch.2018.02.002.

Kruse, S., 2015, Experimental and Numerical Study of MILD Combustion for Gas Turbine Applications, Applied Energy, Vol. 148, pp. 456-465. DOI:10.1016/j.apenergy.2015.03.054

Lefebvre, A. H., and Ballal, D. R., 2010, Gás Turbine Combustion: Alternative Fuels and Emissions, 3rd Edition, CRC Press.

Roache, P. J., Celik, I. B., Ghia, U., Freitas, C. J., Coleman, H., and Raad, P. E., 2008, Procedure for Estimation and Reporting of Uncertainty Due to Discretization in CFD Applications, Journal of Fluids Engineering, Vol. 130. DOI:10.1115/1.2960953.

Silva, R. E. P., 2013, Preliminary Design of a Combustion Chamber for Microturbine Based in Automotive Turbocharger, in: 22nd International Congress of Mechanical Engineering (COBEM), Ribeirão Preto, SP.

Zainal, Z. A., 2017, Combustion Chamber Design and Performance for Micro Gasturbine Application, Fuel Processing Technology, Vol. 168, pp. 258-268. DOI:10.1016/j.fuproc.2017.05.037. 